\title{
EL VIRREINATO DE SICILIA EN LA MONARQUÍA HISPÁNICA: LAS INSTITUCIONES DE GOBIERNO (1665-1675)
}

\author{
María del Pilar MESA CORONADO
}

Recibido: $30 / 11 / 2011$

Aceptado: 04/11/2013

RESUMEN: El presente estudio se centra en el gobierno de uno de los dominios italianos de la Monarquía Hispánica: la isla de Sicilia. Este reino era un enclave esencial de la política exterior de la Corona española en el Mediterráneo y, como tal, necesitaba unas instituciones para su gobierno. A través de los siguientes apartados analizaremos las instituciones del rey en Sicilia y las instituciones del reino durante la regencia de Mariana de Austria.

PALABRAS ClAVE: Monarquía Hispánica, Sicilia, Gobierno, Instituciones, Política Exterior, 16651675.

ABSTRACT: This article is focused in the government of one of the Italian domains of the Spanish Monarchy: the island of Sicily. This kingdom was an important key for the foreign policy of the Spanish Crown in the Mediterranean and, as such, needed some institutions for governance. The following sections we will analyse the king's institutions in Sicily and the institutions of the kingdom during the Mariana of Austria's regency.

KEYWORDS: Spanish Monarchy, Sicily, Government, Institutions, Foreign Policy, 1665-1675.

\section{INTRODUCCIÓN: EL MEDITERRÁNEO EN LA POLÍTICA EXTERIOR DE LA MONARQUÍA HISPÁNICA}

Desde que a finales del siglo XV, Fernando el Católico emprendió una política exterior basada en la conquista de Nápoles y la expansión por el norte de África, el Mediterráneo formó parte de la concepción política española, especialmente, durante los reinados de la dinastía Habsburgo ${ }^{1}$.

${ }^{1}$ G. Galasso (2000). En la periferia del Imperio. La Monarquía Hispánica y el Reino de Nápoles. Barcelona: Península, p. 48. Para la expansión por el Norte de África, véase E. MARTínEZ 
En 1665, la muerte de Felipe IV dejaba a la Monarquía en una situación comprometida, dada la minoría de edad del príncipe Carlos. En el aspecto exterior, el periodo de 1665 a 1675, estuvo marcado por dos factores: la política expansionista de Luis XIV y el temor a la expansión otomana en el Mediterráneo. España se hallaba en aquellos momentos en una frágil situación en el frente portugués, sobre todo a raíz de la derrota en Villaviciosa en 1665. Los portugueses contaban con el apoyo de Inglaterra ${ }^{2}$ y de Francia, naciones que pretendían debilitar el poder de la Monarquía Hispánica. La situación derivó en la firma del tratado de paz del 13 de febrero de 1668, por el que se reconocía la independencia de Portugal ${ }^{3}$.

A este problema, se vino a sumar el de la Guerra de Devolución, que enfrentó a Francia y España por los Países Bajos, debido a la pretensión de Luis XIV de adquirir dicho territorio a través de los supuestos derechos de su mujer María Teresa, hija de Felipe IV. Mientras Luis XIV reclamaba en 1667 sus supuestos derechos, Inglaterra y las Provincias Unidas firmaban una paz, que les permitía el inicio de las conversaciones destinadas a frenar la expansión francesa ${ }^{4}$.

Pese a ello, el fracaso de las armas españolas obligó a Mariana de Austria a desplegar una inusitada actividad diplomática con la que consiguió la mediación del papa Clemente IX en la búsqueda de un acuerdo con Francia ${ }^{5}$. Fruto de sus logros la Triple Alianza, formada por Inglaterra, Holanda y Suecia, contribuyó al cese del conflicto mediante la paz de Aquisgrán 6 . Dicho tratado, firmado el 2 de mayo de 1668, supuso para España la pérdida de ciudades como Charleroi, Mons, Courtrai, Lille, Douai y Oudenaarde, aunque le permitió recuperar el Franco

Ruíz (2008). Los soldados del Rey. Los ejércitos de la Monarquía Hispánica (1480-1700). Madrid: Actas, pp. 683-699.

2 M. Herrero SÁnCHeZ (2000). El acercamiento hispano-neerlandés (1648-1678). Madrid: Consejo Superior de Investigaciones Científicas, p. 355.

${ }^{3}$ H. KAMEn (2000). «España en la época de Luis XIV». En R. MEnÉndeZ PidAl y J.M. Jover ZAMORA. Historia de España. Madrid: Espasa, vol. XXXVIII, p. 212; G. MAURA Y GAMAZO (1942). Vida y reinado de Carlos II. Madrid: Espasa-Calpe, p. 91.

4 M. HeRrero SÁNCHEZ (2000). El acercamiento hispano-neerlandés..., p. 372. Sobre los derechos sucesorios de María Teresa, esposa de Luis XIV, véase C. GómEZ-CEnTURIÓN JiMÉNEZ (2001). «La sucesión a la monarquía de España y los conflictos internacionales durante la menor edad de Carlos II (1665-1679)». En J. Alcalá-Zamora y Queipo De Llano y E. Belenguer (coords.). Calderón de la Barca y la España del Barroco. Madrid: Centro de Estudios Políticos y Constitucionales, vol. I, pp. 816-817.

5 J. A. SÁNCHEZ BELÉN (1999). «Las relaciones internacionales de la monarquía hispánica durante la regencia de doña Mariana de Austria». Studia Historica. Historia Moderna, 20, p. 146.

${ }^{6}$ M. HerRero SÁNCHEZ (2000). El acercamiento hispano-neerlandés..., p. 147. 
Condado. Sin embargo, la paz de Aquisgrán también supuso un freno a las aspiraciones expansionistas de Luis XIV, pues la Triple Alianza se acabaría convirtiendo en el garante de las fronteras centroeuropeas frente a los intereses de la Corona francesa ${ }^{7}$.

Desde comienzos de la década de 1670 , la política francesa se orientó a la recomposición de antiguas alianzas, como la firmada con Inglaterra en junio de 1670, con el objetivo de erosionar las sólidas relaciones hispano-holandesas y desactivar cualquier acuerdo futuro como el logrado por la Triple Alianza. Sin embargo, en agosto de 1673 se acordaba en La Haya una nueva alianza entre Holanda, España, el Sacro Imperio y el ducado de Lorena. El acercamiento inglés a las posiciones holandesas, fraguado con la paz de Westminster el 19 de febrero de $1674^{8}$, dejaba nuevamente aislada a Francia en un contexto internacional en el que la Monarquía española parecía incorporar a su causa a dos nuevos aliados, por otra parte, importantes potencias marítimas ${ }^{9}$.

Durante dicho conflicto, España debió atender tres frentes: los Países Bajos, Cataluña y el Mediterráneo. Fue en este último, donde cabe destacar la guerra de Messina, que comenzó con una revuelta en julio de 1674 dando lugar posteriormente a una guerra, favorecida por el apoyo francés a los rebeldes mesineses en un claro intento por parte de Luis XIV de desestabilizar a la Monarquía española. Pese a ello, España pudo contar en el frente mesinés con el apoyo de la armada holandesa hasta octubre de $1676^{10}$.

Finalmente, se produjo la decisión de Luis XIV de retirarse de Sicilia, pues su posición en la isla no era segura y en 1678 se concretó la firma del tratado de paz de Nimega, por el que se ponía fin a la guerra de Holanda con la pérdida por parte española del Franco Condado, junto con una serie de ciudades en Flandes como

\footnotetext{
7 Véase en M. RiVERo RodRíGuEZ (2000). Diplomacia y relaciones exteriores en la Edad Moderna. 1453-1794. Madrid: Alianza Editorial, p. 149.

${ }^{8}$ C. M. FERnÁNDEZ NADAL (2009). La política exterior de la monarquía de Carlos II. El Consejo de Estado y la embajada de Londres (1665-1700). Gijón: Ateneo Jovellanos, pp. 170-205.

9 J. A. SÁNCHEZ BELÉN (1999). «Las relaciones internacionales de la monarquía hispánica...», p. 157 y p. 165; H. KAMEN. (2000). «España en la Europa de Luis XIV ...», pp. 219-221; M. HeRRERO SÁNCHEZ (2000). El acercamiento hispano-neerlandés..., pp. 375-376.

${ }^{10}$ Para una visión completa de la revuelta de Messina y posterior guerra, véase L. A. RiBOT GARCía (1982). La Revuelta antiespañola de Mesina. Causas y antecedentes (1591-1674). Valladolid: Universidad de Valladolid; L. A. Riвot GARCÍA (2002). La Monarquía de España y la guerra de Mesina (1674-1678). Madrid: Actas.
} 
Cambrai, Valenciennes, St. Omer e Ypres, además de la mitad de la isla de la Española en el Caribe ${ }^{11}$.

Por otra parte, el Mediterráneo occidental comienza a transformarse en estos años en el centro de la presencia de turcos y berberiscos a los que se sumaron los intereses de los pequeños estados italianos y los de potencias como Inglaterra, Francia, Holanda y España. Este interés vino provocado por la intención de controlar las bases marítimas de importancia estratégica y mercantil presentes en este mar.

Para autores como José Alcalá-Zamora, con el tratado de los Pirineos de 1659, se ponía de relieve el fin de la política de los Habsburgo centrada en la zona nórdica y centroeuropea, para dar paso a una política exterior basada en las posesiones mediterráneas ${ }^{12}$.

El Mediterráneo se transforma en el lugar de actuación de la política exterior del reinado de Carlos II anticipando así la política internacional desarrollada por Felipe V. Durante el reinado de Carlos II, el prestigio y la reputación, conceptos, tan claramente defendidos por la dinastía de los Austrias, llevaron a la toma de una serie de medidas pensadas con el fin de mantener las posesiones mediterráneas, tan importantes para las finanzas de la Monarquía así como para la seguridad de la Corte española. Sin embargo, no hay que olvidar como menciona J. AlcaláZamora, que la presencia española en el Mediterráneo al menos frente a la expansión francesa, se mantuvo gracias al interés de otras potencias como Holanda e Inglaterra deseosas por neutralizar al enemigo francés ${ }^{13}$.

En este periodo la Corte madrileña trasladará sus acciones al Mediterráneo en defensa de sus posesiones frente a los posibles ataques berberiscos y otomanos. Con respecto a los ataques berberiscos, producidos desde lugares como Argel, Túnez o Trípoli, con el objeto de capturar prisioneros en tierras españolas o italianas, la Corona española contó desde 1648 con el apoyo de la república holandesa. Desde aquel momento, Holanda solicitará a la Monarquía Hispánica la colaboración naval y estratégica para liberar la cuenca mediterránea de los ataques

${ }^{11}$ H. Kamen. (2000). «España en la Europa de Luis XIV...», pp. 222-226; J. H. ElliotT (2005). La España Imperial, 1469-1716. Barcelona: Vicens Vives, p. 397.

12 J. AlCAlÁ-Zamora y QUeIPo DE Llano (1976). «Razón de Estado y geoestrategia en la política italiana de Carlos II: Florencia y los Presidios (1677-1681)». Boletín de la Real Academia de la Historia, 173, pp. 300-314.

13 Ibidem., pp. 352-353; D. SALINAS (1989). La diplomacia española en las relaciones con Holanda durante el reinado de Carlos II (1665-1700). Madrid: Ministerio de Asuntos Exteriores, pp. 121-122. 
berberiscos, que por otra parte perjudicaban su comercio en la zona. Además, entre 1667 y 1673, la Monarquía otorgó patentes de corso a armadores flamencos y mallorquines con el objeto de que las costas españolas e italianas quedasen liberadas del peligro de los corsarios del norte de África. Acciones a las que se sumaron las expediciones de asistencia enviadas a territorios como Ceuta y Orán que durante los últimos años de la Regencia sufrieron los ataques de aquéllos ${ }^{14}$.

Con respecto al problema otomano, la paz de Vasvar en 1664 entre el Imperio Otomano y el emperador Leopoldo I, contribuyó a la estabilización del frente húngaro. La Sublime Puerta, liberada del frente centroeuropeo podía concentrarse en otros territorios ${ }^{15}$.

El conflicto se desvió a la isla de Creta. La guerra de Candía, que enfrentó a venecianos y otomanos por el dominio de la isla desde 1645, se transformó en sus últimos años en un asedio de la plaza de Candía, iniciado el 21 de mayo de 1667 y mantenido hasta la rendición de ésta por parte de Francesco Morosini, el 5 de septiembre de 1669. El fracaso de su defensa por parte de la República de Venecia, la Santa Sede, la Orden de Malta, las Coronas de España y Francia, del Sacro Imperio, y otra serie de principados, durante los años 1668 y 1669, supuso la pérdida de este antemural de la Cristiandad ${ }^{16}$.

El temor al traslado de las hostilidades por parte de los otomanos a los dominios italianos de la Monarquía Hispánica provocó la alarma en territorios como el reino de Sicilia, pues se sucedieron los avisos sobre posibles ataques a dichas posesiones de la Monarquía a pesar de que en muchos casos fueron contradictorios pues un mismo territorio podía recibir los avisos de ataque a Polonia, Venecia, Malta o incluso a los reinos de Nápoles y Sicilia ${ }^{17}$.

${ }^{14}$ Ibidem., pp. 377-384.

15 M. JAČOV (2001). L' Europa tra conquiste ottomane e leghe sante. Città del Vaticano: Biblioteca Apostolica Vaticana, p. 110; S. J. SHAw (1977). History of the Ottoman Empire and Modern Turkey. Cambridge: University Press, vol. I, p. 212; R. MANTRAN (1989). Histoire de l'Empire Ottoman. Poitiers: Fayard, pp. 244-245.

${ }^{16}$ K. M. Setton (1991). Venice, Austria, and the Turks in the Seventeenth Century. Philadelphia: The American Philosophical Society, p. 228. Para el estudio de las causas del conflicto cretense, la vinculación de la orden de Malta con el mismo, así como sus consecuencias, véase A. BROGINI (2006). Malta, frontière de Chrétienté (1530-1670). Rome: École Française de Rome, pp. 533-554.

17 A.G.S., Secretarías Provinciales, leg. 1.044, doc. Nápoles, 12 de mayo de 1671. Sirva de ejemplo lo acaecido en el año 1671 cuando se produjo un incremento de los avisos por la incertidumbre de los designios del sultán otomano. Los avisos de Levante de aquel año no coincidieron en sus previsiones, ofreciendo diversos destinos que podían sufrir un ataque de los turcos, tales como: el reino de Sicilia, la zona de la Puglia y el reino de Polonia. Para profundizar en 


\section{EL REINO DE SICILIA EN LA ESTRATEGIA DEFENSIVA DE LA MONARQUÍA HISPÁNICA}

La isla de Sicilia se convirtió desde su incorporación a la Corona de Aragón en un enclave fundamental para la estrategia defensiva del Mediterráneo. En plena época medieval, este reino pertenecía a la dinastía de los Staufen, cuyo rey Manfredo de Hohenstaufen, había sufrido la oposición del papa desde su coronación en 1258. El pontífice había entregado el trono napolitano a un hermano del rey francés, Carlos de Anjou. El enfrentamiento entre ambos y la victoria de Carlos de Anjou sobre Manfredo y sus herederos terminaron vinculando los derechos de los Staufen en Constanza, hija de Manfredo y esposa de Pedro de Aragón, rey desde $1276^{18}$.

El 31 de marzo de 1282 comenzaron las Visperas Sicilianas, una rebelión de los sicilianos contra la presencia francesa en la isla, en la que se pidió la ayuda de Pedro de Aragón, quien terminó por ser coronado como rey de Sicilia ${ }^{19}$. Sin embargo, los derechos de los Anjou fueron defendidos por la Santa Sede dando lugar a una guerra. En 1295 el problema fue solucionado a través del Tratado de Anagni. Por éste, el hermano pequeño del rey Jaime II de Aragón, Federico, se convertía en el rey siciliano, pero a través de la investidura del Papa. En 1302 se firmaba el Tratado de Caltabellotta por el que los Anjou de Nápoles reconocían como rey vitalicio de la isla de Sicilia a Federico III, a cambio de que éste se casara con Leonor, una hija de Carlos de Anjou y al morir dejase el trono en manos de los Anjou. Este tratado se convirtió en un fracaso pues al morir Federico III, el trono fue heredado por su hijo Pedro II.

A éste le sucedieron su hijo Ludovico y Federico IV, cuya hija María contrajo matrimonio con Martín «el Joven», hijo del rey Martín I de Aragón. Cuando

este episodio de incertidumbre, véase M. P. MESA CORONAdo (2012). «Sicilia en la estrategia defensiva del Mediterráneo (1665-1675)». En SAnz CAMAÑes, Porfirio (ed.). Tiempo de cambios. Guerra, diplomacia y política internacional de la Monarquía Hispánica (1648-1700). Madrid: Actas, pp. 392-393. Para la importancia de los «Avisos de Levante» y de los reinos de Nápoles y Sicilia como centros receptores de este tipo de información, véase M. A. BUNES IBARRA (2010). «El control de la información del Mediterráneo desde Nápoles y Sicilia en la época de Felipe III». En J. Martínez Millán y M. Rivero Rodríguez (coords.), Centros de Poder Italianos en la Monarquía Hispánica (siglos XV-XVIII). Madrid: Polifemo, vol. I, pp. 351-373; y E. Solá CASTAÑo (2005), Los que van y vienen. Información y fronteras en el Mediterráneo clásico del siglo XVI. Alcalá de Henares: Servicio de Publicaciones. Universidad de Alcalá de Henares.

18 Cfr. R. Pérez Bustamente (2000). El Gobierno del Imperio Español. Los Austrias (15171700). Madrid: Comunidad de Madrid. Consejería de Educación, p. 225.

${ }^{19}$ L. A. Ribot García (1982). La Revuelta antiespañola de Mesina ..., p. 37. 
Martín «el Joven», rey de Sicilia, murió en 1409 dejó el trono en poder de su padre Martín I de Aragón y II de Sicilia, vinculándose desde dicho año a la principal rama de la Corona de Aragón. Al morir éste último sin descendencia, el reino de Sicilia quedó en manos de Blanca de Navarra, en calidad de «vicaria del reino» por su condición de segunda esposa de Martín I de Sicilia. En 1415 el duque de Peñafiel, segundo hijo del rey Fernando I de Aragón, se convertiría en el nuevo rey de la isla ${ }^{20}$.

Desde su incorporación a la Corona de Aragón la isla de Sicilia fue considerada como un dominio estratégico en la defensa mediterránea. No obstante, no estuvo sola, pues a lo largo del Mediterráneo la dinastía Habsburgo contó con toda una serie de enclaves periféricos que tanto en el Norte de África como a lo largo de las costas españolas e italianas, le permitieron defender el centro de la Monarquía.

En el periodo que nos ocupa, como se mencionó anteriormente, los dos principales peligros en el Mediterráneo fueron: el temor a la expansión otomana por el Mediterráneo Occidental, sobre todo a raíz de la conquista de Candía en 1669; así como el incremento de la presencia francesa en dicho mar. Por lo que se refiere al enfrentamiento entre la Cristiandad y el Islam, la Monarquía Católica contaba al inicio de la Regencia con toda una serie de territorios acostumbrados desde hacía siglos a esta lucha. En el Norte de África se hallaban: Ceuta, Melilla, Orán, Mazalquivir y el Peñón de Vélez. Estos territorios junto con alguno más como Alhucemas, incorporado en 1673, constituyeron una avanzadilla frente a la amenaza otomana, ya que desde ellos se podía obtener información sobre la proximidad de las armadas turcas, así como una defensa frente a Argel, principal sede de los corsarios berberiscos y centro receptor de las noticias del sultán otomano $^{21}$.

A éstas, se añadían los reinos y territorios españoles a lo largo de la costa mediterránea, es decir: los reinos de Granada, Murcia, Valencia, Mallorca y el Principado de Cataluña. Finalmente, las posesiones del Mediterráneo central, principalmente Cerdeña, los Presidios Toscanos, Nápoles y Sicilia. Entre la Italia meridional, y los dominios españoles en los Países Bajos, el ducado de Milán se convirtió en una plaza de armas estratégica para la Monarquía y en un eficaz enlace con los territorios de la Europa central y septentrional ${ }^{22}$. No obstante, para dicha

${ }^{20}$ R. PÉRez Bustamente (2000). El Gobierno del Imperio Español..., pp. 226-227.

21 B. AlONSO ACERo. (2000). Orán-Mazalquivir, 1589-1639: una sociedad española en la frontera de Berbería. Madrid: Consejo Superior de Investigaciones Científicas, p. 11.

22 G. SignorotTo. (2006). Milán Español. Guerra, instituciones y gobernantes durante el reinado de Felipe $I V$. Madrid: La Esfera de los Libros, p. 101. Véase también para el aspecto militar, 
función contó con las numerosas asistencias militares y apoyo logístico transferidas desde los reinos italianos del sur ${ }^{23}$.

De esta forma, los territorios italianos se complementaban unos a otros, mientras las posesiones del sur de Italia y el dominio español de Milán proporcionaron los recursos humanos y económicos necesarios para mantener la posición española en Centroeuropa y en el Mar del Norte ${ }^{24}$.

Todo parece indicar que la isla de Cerdeña tuvo una menor importancia tanto política como financiera en la Monarquía ${ }^{25}$, debido entre otros motivos a la continua presión corsaria y turca que sufrió. Sin embargo, disfrutaba de una situación envidiable por su cercanía a los demás territorios del Mediterráneo ya fueran los españoles de la costa levantina o los italianos de Nápoles, Sicilia y los Presidios Toscanos. Por tanto, al igual que estos últimos, se constituyó en un enclave frente a la expansión turca obligándole a desarrollar sus sistemas defensivos en el siglo XVI, sobre todo, a raíz de la caída de La Goleta en $1574^{26}$.

Los Presidios Toscanos, incorporados en 1557, estaban constituidos por Orbetello, Porto Ercole, Porto San Stefano, Talamone, Ansedonia, Piombino, y la isla de Elba. Al igual que las demás posesiones italianas, tenían una posición

especialmente el ejército de Milán, L. A. RiBot García (1990). «Milán, plaza de Armas de la Monarquía». Investigaciones Históricas, 10, pp. 203-238.

23 L. A. Ribot García (1990). «Milán, Plaza de Armas de la Monarquía...», p. 231. Para comprender el valor estratégico del ducado de Milán en la defensa de la Monarquía Hispánica durante el reinado de Carlos II, véanse los recientes estudios de D. MAFFI (2010). La cittadella in armi. Esercito, società e finanza nella Lombardia di Carlo II (1660-1700). Milano: Franco Angeli; C. STORRS (1997), «The Army of Lombardy and the Resilence of Spanish Power in Italy in the Reign of Carlos II (1665-1700). Part I». War in History, 4, pp. 371-397; y C. STORRS (1998). «The Army of Lombardy and the Resilence of Spanish Power in Italy in the Reign of Carlos II (1665-1700). Part II». War in History, 5, pp. 1-21.

24 J. AlcAlÁ-Zamora y Queipo DE Llano (1976). «Razón de Estado y geoestrategia en la política italiana de Carlos II...», p. 307. Para conocer la participación de la isla de Sicilia en la política hegemónica de la Corona española a través de sus aportaciones en recursos financieros, véase M. AYMARD (1972). «Bilancio d'una lunga crisi finanziaria». Rivista Storica Italiana, LXXXIV, IV, pp. 988-1.021; y D. LigReSTI (1997). «I bilanci secenteschi del Regno di Sicilia». Rivista Storica Italiana, CIX, III, pp. 894-937. Para el caso del reino de Nápoles, véase A. CALABRIA (2002). The cost of empire. The finances of the Kingdom of Naples in the Time of Spanish Rule. Cambridge: University Press.

${ }^{25}$ A. Musi (2001). L'Italia dei Vicerè. Integrazione e resistenza nel sistema imperiale spagnolo. Cava de Tirreni: Avagliano Editore, p. 18. Para profundizar en la situación política y económica del reino de Cerdeña, véase J. DAY, B. AnAtra y L. SCARAfFiA (1984). La Sardegna mediovale e moderna. Torino: UTET.

${ }^{26}$ E. MARTínEz Ruíz (2008). Los soldados del Rey. Los ejércitos..., pp. 751-752. 
estratégica que les permitió servir de enlace entre la zona de Nápoles y GénovaMilán, así como entre el Estado florentino y la Italia central ${ }^{27}$. Asimismo, apoyaron la defensa frente a los ataques turco-berberiscos e impidieron la expansión de Francia por la zona sienesa ${ }^{28}$.

Mientras, los reinos de Nápoles y Sicilia, junto con Malta, destacaron por su condición de «bisagra central del mar» ${ }^{29}$, es decir, por su situación frente al peligro turco en el Mediterráneo, el reino de Sicilia ha sido denominado también con distintos términos con los que se ha señalado su importancia geoestratégica, tales como: «fortaleza», «antemural», «frontera de la Cristiandad» y «baluarte» ${ }^{30}$.

De hecho, la situación del virreinato de Sicilia continuó siendo indispensable durante la Regencia de Mariana de Austria, e incluso se convirtió en una cuestión perentoria a partir de 1669 , debido a la caída de Candía, y con ello, a los temores generados por una posible invasión otomana en los dominios italianos de la Monarquía, especialmente en los reinos de Sicilia y Nápoles. Aunque como resultó habitual, los avisos de una posible invasión quedaron sin efecto en Sicilia, la isla continuó durante este periodo constituyendo un «baluarte contra los infieles».

\section{LAS INSTITUCIONES DEL REY EN SICILIA}

Con el fin de gobernar adecuadamente este enclave, existían una serie de instituciones que pueden dividirse en dos categorías: las instituciones del rey y las instituciones del reino de Sicilia.

La isla de Sicilia era un reino paccionado porque su incorporación a la Corona no se había producido a través de una conquista sino de forma voluntaria tras la solicitud de ayuda a Pedro III de Aragón al que después nombraron su rey ${ }^{31}$. Se vinculó a la Corona a través de un contrato firmado por los monarcas y recogido en los Capitula Regni Siciliae, una compilación legislativa basada en las peticiones que le fueron concedidas al Parlamento por los reyes en contraposición de los

27 J. Alcalá-Zamora y Queipo DE Llano (1976). «Razón de Estado y geoestrategia en la política italiana de Carlos II...», pp. 307-308.

${ }^{28}$ E. MARTínez Ruíz (2008). Los soldados del Rey. Los ejércitos..., p. 756.

${ }^{29}$ F. BRAUDEL. (2005). El Mediterráneo y el mundo mediterráneo en la época de Felipe II. $2^{\mathrm{a}}$ ed.

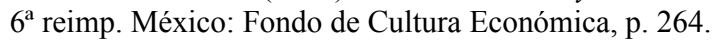

30 D. Ligresti (2003). «La Sicilia frontiera». En F. BEnigno y G. Giarrizzo (a cura di). Storia della Sicilia, vol. I. Roma: Editori Laterza, p. 143; V. FAVARÒ (2004). «La Sicilia Fortezza del Mediterraneo». Mediterranea. Ricerche storiche, 1, pp. 31-48.

${ }^{31}$ A. Musi (2001). L'Italia dei Vicerè..., p. 67. 
donativos y las concesiones aprobadas por el reino ${ }^{32}$. Este tipo de acuerdo se asemejaba a la situación de otros reinos como el de Aragón en donde su carácter consuetudinario y pactista estuvo ligado a la aplicación de ciertos límites al poder real, basados en el respeto a ciertos privilegios, franquicias o leyes fundamentales provenientes de la época medieval ${ }^{33}$.

En el reino de Sicilia conllevó la obligación de los monarcas españoles de respetar las instituciones autóctonas del reino y, por tanto, ciertas limitaciones como la obligación de los reyes de jurar la observancia y conservación de las constituciones, capítulos y privilegios del reino. Fue el caso de los privilegios aprobados en 1446 por Alfonso V. Por ellos, los oficios y magistraturas del reino se reservarían a naturales. Además, no podría dictarse sentencia desde el extranjero, se concedía el mero y mixto imperio a los nobles parlamentarios y se reservaba la mitad de los oficios y beneficios eclesiásticos para los sicilianos ${ }^{34}$. Por tanto, mientras el rey respetara los privilegios del reino tendría garantizada la fidelidad de los sicilianos, puesto que se la habían otorgado voluntariamente ${ }^{35}$.

No obstante, Sicilia formaba parte de la Monarquía Hispánica y como tal dependía de la administración central de ésta, representada entre otras instituciones por el Consejo de Italia. Este Consejo, habría tenido su origen en 1555 en Londres, cuando el futuro rey Felipe II entregó una instrucción a una serie de personas destinadas a tratar los asuntos de Nápoles y Milán. Su primer presidente, nombrado en 1558, fue Diego Hurtado de Mendoza. La primera instrucción a los integrantes de dicho Consejo no llegaría hasta finales de 1559, cuando Felipe II incorporaba «oficialmente» el virreinato de Sicilia al Consejo ${ }^{36}$.

Este Consejo estaba compuesto por seis regentes, dos por cada provincia: Nápoles, Sicilia y Milán, uno de ellos español y el otro local. Se encargarían de aconsejar al rey en asuntos que no fueran propiamente del Consejo de Estado y

${ }^{32}$ M. RiVERo RodrígueZ (2004). «Italia en la Monarquía Hispánica (siglos XVI-XVII)». Studia Historica. Historia Moderna, 26, p. 34.

${ }^{33}$ Dicha similitud también ha sido recogida por C. STORRS (2006). The Resilence of the Spanish Monarchy, 1665-1700. New York: Oxford University Press, p. 223. Para una visión más detallada de las características del reino de Aragón, véase P. SANZ CAMAÑEs (1997). Política, hacienda y milicia en el Aragón de los últimos Austrías entre 1640 y 1680. Zaragoza: Institución «Fernando el Católico», pp. 31-32.

34 Cit. L. A. Ribot García (1982). La Revuelta antiespañola de Mesina ..., p. 38; M. Rivero RodríGUEZ (2004). «Italia en la Monarquía Hispánica (siglos XVI-XVII)...», p. 34.

${ }^{35}$ Cfr. H. G. Koenigsberger (1989). La práctica del Imperio. Madrid: Alianza Editorial, p. 59.

${ }^{36}$ M. Rivero RodríGUez (1998). Felipe II y el Gobierno de Italia. Madrid: Sociedad Estatal para la Conmemoración de los Centenarios de Felipe II y Carlos V, pp. 50-51 y p. 63. 
aunque se les atribuyó ciertas competencias en justicia, lo cierto es que hasta el siglo XVII no pudieron tratar causas civiles ni criminales en el reino de Sicilia ${ }^{37}$.

El Consejo de Italia se encargaba de la administración de los dominios italianos, en especial, de las finanzas, el comercio y las aduanas y del nombramiento de oficiales civiles y militares, así como de la concesión de privilegios, títulos y beneficios. Todos los asuntos importantes de estado estaban reservados para el Consejo de Estado, encargado de la política exterior de la Monarquía, lo que no impidió que, sobre todo en el siglo XVII, surgieran conflictos institucionales entre uno y otro consejo por las competencias asignadas a cada uno de ellos ${ }^{38}$.

Al frente de la administración territorial del reino de Sicilia estaba la figura del virrey. Éste disponía, al menos en teoría, de la completa dirección del territorio y podía convocar y disolver el Parlamento, exigir nuevos impuestos y publicar pragmáticas a través del Sacro Consejo. Se entendía directamente con la Curia Romana para los asuntos eclesiásticos y podía impedir la publicación de bulas papales en el reino. A ello, se unía su función de capitán general, por la que estaba al frente de la defensa de la isla y ejercía su mandato sobre las fuerzas militares del reino ${ }^{39}$.

Su origen se sitúa en la imposibilidad de los reyes de la Corona de Aragón de estar presentes en cada uno de sus reinos, principados y señoríos de su Corona, lo que hizo necesario el envío desde el siglo XIII de delegados del monarca a estos lugares. Al ampliarse la Corona de Aragón en el siglo XIV dichos representantes adquirieron la función del vicariato convirtiéndose a partir de entonces en los Alter ego u otro yo del Rey. Éstos recibieron la denominación de vicerreges, visoreys o virreis $^{40}$. En un primer momento, estos virreyes fueron nombrados entre los

${ }^{37}$ Ibidem., p. 67.

38 H. G. Koenigsberger (1989). La práctica..., pp. 70-78. Para conocer la estructura y el funcionamiento del Consejo de Estado, véase F. BARRIOS (1984). El Consejo de Estado de la Monarquia Española (1521-1812). Madrid: Consejo de Estado.

39 Ibidem., p. 110. Para profundizar en la biografía y el gobierno de los virreyes de Sicilia de los siglos XV-XVII, véase D. LigreSTI (2007). Sicilia aperta (secoli XV-XVII). Mobilità di uomini e idee. Palermo: Associazione non profit «Mediterranea», pp. 9-69; V. AURIA (1697). Historia cronologica delli signore vicere di Sicilia: dal tempo che mancò la personale assistenza de'Serenissimi Rè di quella: cioe dall anno 1409 sino al 1697 presente. Palermo: Pietro Coppola; y G. E. DI BLASI Gambacorta (1790). Storia Cronologica dei vicerè, luogotenenti, e presidenti del Regno di Sicilia. Palermo: Dalle Stampe di Solli.

${ }^{40}$ M. RiVERo RodRíGUEZ (1989). «Doctrina y práctica política en la monarquía hispana; Las instrucciones dadas a los virreyes y gobernadores de Italia en los siglos XVI y XVII». Investigaciones históricas: época moderna y contemporánea, 9, pp. 201-202. 
miembros de la familia real hasta que la expansión de la Monarquía impidió cubrir de este modo cada una de las plazas en las distintas posesiones. Desde entonces, comenzaron los nombramientos de miembros de la nobleza como virreyes de las posesiones aragonesas. Es el caso del virreinato de Sicilia en donde el reinado de Juan II de Aragón se caracterizó por la elección de nobles catalanes y valencianos para el desempeño de este cargo ${ }^{41}$.

Posteriormente, la elección de estos nobles se vio favorecida por la idea de la Monarquía basada en la conveniencia de la elección en un extranjero para el gobierno del reino, frente al de un natural, para evitar se involucrase de tal forma en los intereses locales, que le pudieran enfrentar a las órdenes reales. Esta decisión y la necesidad de compensar las aspiraciones de ciertos linajes nobiliarios motivaron la designación de ciertos nobles para el cargo de virrey en los siglos XVI y XVII ${ }^{42}$. No obstante, el cargo de virrey estuvo siempre sujeto a las tensiones interiores del reino y a la lucha de las distintas facciones existentes en la Corte de Madrid. Lo que comenzaba como una protesta en el virreinato, provocada generalmente por ciertos sectores de la nobleza, daba lugar a la destitución de un virrey al combinarse la protesta con el apoyo de los sectores influyentes en la Corte española ${ }^{43}$. Ello derivó de la necesidad que tuvo la Corona de contar con la nobleza feudal del reino de Sicilia, pues ésta controlaba grandes extensiones territoriales y disfrutaba de un importante poder, que se vio incrementado cuando las necesidades financieras de la Corona favorecieron la extensión de los dominios baronales ${ }^{44}$.

41 Cit. C. Hernando SÁnChez (2004). «Los virreyes de la Monarquía Española en Italia. Evolución y práctica de un oficio de gobierno». Studia Historica. Historia Moderna, 26, pp. 50-51, C. GiARdina (1931). «L'istituto vicerè di Sicilia (1415-1798)». Archivio Storico Siciliano, vol. LI, pp. 195-196.

42 Ibidem., pp. 57-58; C. GIARDINA (1931). «L'istituto vicerè...», p. 199. Sirva de ejemplo el caso del príncipe de Ligne, virrey de Sicilia entre 1670 y 1674, elegido por su condición de noble y su vinculación a Juan José de Austria. Véase en M. RIVERO RoDRÍGUEZ (2009). «Virtud cristiana de la nobleza de Sicilia: La interrupción de la asistencia de los blancos de Palermo a los ajusticiados (16701675)». En M. Rivero RodríGUEZ (ed.). Nobleza hispana, nobleza cristiana. La Orden de San Juan. Madrid: Polifemo, vol. I, p. 668.

${ }^{43}$ R. VILLARI (1996). «España, Nápoles y Sicilia. Instrucciones y advertencias a los virreyes». En EnCiso Recio, L. M. (coord.). La politica de Felipe II. Dos estudios. Valladolid: Universidad de Valladolid, 1996, p. 34. Estas facciones contaban con miembros vinculados por profundas raíces a ciertas provincias de la Monarquía, lo que influía en las acciones llevadas a cabo por éstas. Véase en A. Álvarez-Ossorio Alvariño (2001). «Neoforalismo y Nueva Planta: el gobierno provincial de la monarquía de Carlos II en Europa». En J. AlCALÁ-ZAMORA y QueIPo de Llano y E. Belenguer (coords.). Calderón de la Barca y la España del Barroco. Madrid: Centro de Estudios Políticos y Constitucionales, vol. I, p. 1.083.

${ }^{44}$ Véase L. A. RiBot GARcía (1982). La Revuelta antiespañola de Mesina..., p. 42. También en H. G. Koenigsberger (1989). La práctica..., p. 164. De hecho, la reactivación de la política 
El cargo de virrey tuvo sus luces y sombras pues estuvo marcado por una alternancia entre el poder de los virreyes y las limitaciones propias de esta figura. En Sicilia, los virreyes se vieron limitados por las instrucciones del rey y el obligado respeto a las inmunidades sicilianas, sin olvidar las disputas entre las grandes familias del reino y la actitud de sus ministros, que en muchos casos se pasaron a la oposición, mostrándose contrarios al poder de los virreyes ante el monarca ${ }^{45}$. Este cargo, restringido a tres años por los Reyes Católicos, para evitar el arraigo de los virreyes al ámbito social y político del territorio, fue percibiendo paulatinamente las restricciones de sus funciones desde el reinado de Felipe II. Con la fijación de la Corte en Castilla se incrementó la necesidad de reforzar la presencia de los virreyes en las posesiones de la Corona, a la vez que dio lugar a un aumento de la supervisión y delimitación de sus funciones ${ }^{46}$. De hecho, en la segunda mitad del siglo XVI el alter nos comenzó a concebirse de una forma más restringida entendiéndose como una autorización del virrey en lo público. Es decir, el rey delegaba sólo un aspecto de la potestad regia, la potestad ordinaria, mientras que la potestad absoluta se mantenía intransferible a través de la persona del soberano. La función del doble del rey se convertía en simbólica ${ }^{47}$. En este proceso de reducción de poder se han enmarcado la creación del Consejo de Italia, el desarrollo de las Instrucciones o la oposición de la Inquisición ${ }^{48}$.

En este sentido, según Manuel Rivero, el Consejo de Italia habría sido creado como una nueva institución con la que reducir la capacidad de patronazgo de los

hegemónica de la Monarquía en Europa durante el reinado de Felipe IV conllevó el consiguiente incremento de las aportaciones tanto financieras como humanas en territorios como Sicilia, Nápoles y Cerdeña. Dichas aportaciones, en el caso de Sicilia, supusieron el empleo de medidas como la venta del patrimonio real, el aumento de la presión fiscal indirecta y de la presión fiscal directa. Estas medidas y el progresivo endeudamiento de la Corona española provocado también por el recurso al capital privado, han llevado a autores como Romualdo Giuffrida a defender la teoría de un debilitamiento de las instituciones de la Corona conocido como refeudalización, es decir, la abdicación por parte de la Monarquía en sus dominios a favor de la burguesía y de la nueva nobleza. Véase en R. GIUFFrIDA (1976). «La politica finanziaria spagnola in Sicilia da Filippo II a Filippo IV (1556-1665)». Rivista Storica Italiana, LXXXVIII, II, pp. 328-329.

${ }^{45}$ H. G. Koenigsberger (1989). La práctica ..., p. 196.

46 D. Ligresti (2007). Sicilia aperta..., p. 19; M. Rivero Rodríguez (1998). Felipe II y el Gobierno..., 1998, p. 73; C. HERnANDO SÁNCHEZ (2004). «Los virreyes de la Monarquía Española en Italia...», p. 56.

${ }^{47}$ Cfr. M. Rivero Rodríguez (1989). «Doctrina y práctica política en la monarquía hispana...», p. 202-203. Véase también en P. CORSETO (1984). «Instrucción del regente don Pedro Corseto para el príncipe Filiberto quando fue al virreinato de Sicilia», en V. ScIUTI RUSSI. Il Governo della Sicilia in due Relazioni del Primo Seicento. Napoli: Jovene Editore, p. 57.

${ }^{48}$ C. Giardina (1931). «L'istituto vicerè...», p. 262 y p. 269. 
vicarios reales, reintegrándose en la persona del rey, anulando el desarrollo de las cortes virreinales como centros de poder ${ }^{49}$.

A ello se unirían las Instrucciones entregadas a los virreyes antes de la toma de posesión. Éstas eran dos: una pública u ordinaria y otra secreta. La primera iba destinada al virrey y a los magistrados, autoridades y miembros de las instituciones estamentales del reino. La segunda, estaba dirigida únicamente al virrey y su nivel informativo era más amplio. Dichas instrucciones tenían por objeto aclarar las funciones que debía llevar a cabo un virrey en el desempeño de este cargo. Éstas eran fundamentalmente tres: la defensa de la fe católica frente a los herejes e infieles, la defensa del patrimonio real frente al exterior; y la defensa de la justicia y protección de los vasallos. En éstas se recogía la información necesaria sobre el reino a gobernar, tal como sus instituciones, administración, problemas políticos, sociales y económicos. De las tres funciones del virrey según este tipo de documento, la explicación sobre la defensa frente al exterior se realizaba en la instrucción secreta incluyéndose en ella toda una serie de consejos estratégicos y militares. Sin embargo, las otras dos funciones tenían por objeto la conservación de la Monarquía por lo que las instrucciones se detenían con mayor profundidad en la descripción de estos puntos. Con el paso del tiempo estas instrucciones dejaron de tener un carácter orientativo para transformarse en un texto normativo al que debían someterse los virreyes especialmente en el siglo XVII ${ }^{50}$.

Este es el caso de las obligaciones que encontramos en la instrucción que se otorgó en 1665 a Pedro de Aragón para el desempeño del cargo de virrey de Nápoles. Al margen de las explicaciones oportunas sobre las instituciones del reino a las que debía respetar el virrey, se le recordaba su obligación de mantener correspondencia con los otros virreyes, gobernadores y embajadores de la Monarquía en Italia con el objeto de estar siempre atento a cualquier problema que pudiera ir en contra del servicio al rey y, por tanto, contra la máxima de la conservación de la Monarquía ${ }^{51}$.

49 Véase M. Rivero RodríGuez (1998). Felipe II y el Gobierno ..., p. 73.

${ }^{50}$ M. RIVERO RODRÍGUEZ (1989). «Doctrina y práctica política en la monarquía hispana...», pp. 198-204; (2008). «Una monarquía de casas reales y cortes virreinales». En J. Martínez Millán y M. A. VISCEGLIA (coords.). La monarquía de Felipe III. Madrid: Mapfre, vol. I, pp. 58-59; (2011). La edad de oro de los virreyes. El virreinato en la Monarquía Hispánica durante los siglos XVI y XVII. Madrid: Akal, pp. 212-215.

51 Archivo Histórico Nacional [A.H.N.], Estado, leg. 2010-1, doc. Instrucción a Don Pedro de Aragón para el virreinato de Nápoles. Las instrucciones consultadas del reino de Sicilia corresponden a periodos anteriores o posteriores a la regencia de Mariana de Austria. Por ello, hemos preferido analizar el ejemplo de una instrucción otorgada para el reino de Nápoles, pues los puntos analizados 
Centrándonos en los aspectos defensivos, en el capítulo séptimo de la instrucción, se recordaba al virrey la amenaza que suponía para el reino de Nápoles la presencia de los otomanos en el Mar Mediterráneo, por lo que se le ordenaba tuviera prevenidas las costas y se valiese de espías de Levante para estar bien informado de las tentativas turcas y comunicarlas a la Corte y, en su caso, al resto de los virreyes de Italia:

«La Armada Turquesca se ha hecho tan familiar en los Mares de Italia en daño de mis Reynos, señoríos y de mis confederados y Amigos, speçialmente de aquel Reyno por ser el primero en que toca y tener la costa tan larga, que será neçessario estar sobre avisso en guardar la tierra de marina y tener ciertos y continuos avissos por medio de espias de lo que de aquellas partes de levante se entendiere y dármele a sus tiempos y a los otros mis Virreyes y ministros señaladamente a los delas Islas porque se hallen prevenidos $y$ preparados delo que para su buena guarda y defenssa se requiere» ${ }^{52}$.

A continuación se le ordenaban toda una serie de cuestiones que debía cumplir para mantener una buena defensa del reino frente a otomanos u otro tipo de enemigos. Así, debía actuar contra la proliferación de las «plazas muertas» o plazas ocupadas por personas que no cumplían los requisitos necesarios para obtenerlas y llegaban a las mismas en virtud de recompensas por sus servicios militares a la Monarquía. Además, estaba obligado a vigilar que la paga de la gente de guerra se destinase a la gente que efectivamente servía en sus puestos. Asimismo, el alojamiento de la gente de guerra en los pueblos debía ser supervisado con el fin de evitar cualquier tipo de agravio o abuso sobre la población local. No obstante, en caso de producirse algún perjuicio sobre el entorno, se debía informar del abandono de dicho alojamiento con el objeto de evitar los fraudes que cometían algunos oficiales para cambiar de emplazamiento a la tropa sin justificación alguna. Finalmente, para la defensa del reino se precisaba de la visita a los castillos y fortalezas napolitanas con el fin de mantenerlos en buen estado, con suficientes provisiones y la guarnición militar requerida ${ }^{53}$.

en estas páginas son muy similares a los contenidos en las instrucciones para la isla de Sicilia. De esta forma, nos hemos centrado únicamente en los apartados de carácter defensivo, más propios del tema de estudio de la tesis doctoral desarrollada.

52 Ibidem.

53 Ibidem, capítulos 115, 118, 138, 139, 145 y 146. Sobre los agravios que solía sufrir la población durante los alojamientos de los soldados en los distintos territorios de la Monarquía Hispánica, véase F. CORTÉS CORTÉs (1996). Alojamientos de soldados en la Extremadura del siglo XVII. Mérida: Editora Regional de Extremadura; y P. SANZ CAMAÑES (2004). «El peso de la milicia. 'Alojamiento foral' y conflicto de jurisdicciones en la frontera catalano-aragonesa durante la guerra de Cataluña (1640-1652)». Revista de Historia Moderna, 22, pp. 173-207. 
Por tanto, con instrucciones como ésta se pretendía en primer lugar mantener el estado defensivo de los virreinatos a la vez que se otorgaban toda una serie de normas, ya fueran de carácter militar como jurídico, con las que se pretendía recortar el poder de estos virreyes. Sin embargo, estos procedimientos generaron una contradicción puesto que por un lado se pretendía ordenar el funcionamiento de la institución virreinal, mientras que por el otro los virreyes disfrutaban de cierta autonomía gracias a la imagen pública del alter ego. Es decir, si el virrey incumplía algún mandato o llevaba a cabo alguna medida en contra de las órdenes reales, sólo podía ser amonestado en privado dado que el virrey continuaba siendo el alter ego del rey en el aspecto público, y no podía recriminarse su actitud o afearse su conducta sin que peligrase su prestigio ante sus vasallos ${ }^{54}$.

Por último, otra de las dificultades con las que se encontraron los virreyes de Sicilia la constituyó la Inquisición. Ambas instituciones, la virreinal y la Inquisitorial, eran representantes del poder real en la isla lo que fue foco de no pocos conflictos. A ello contribuyó, la independencia de la Inquisición con respecto al virrey, pues los inquisidores eran nombrados directamente por la Suprema de Madrid con la aprobación del soberano y la presencia cada vez más numerosa de miembros de la nobleza siciliana en dicho organismo. Esta nobleza se opuso en numerosas ocasiones a los virreyes y se vinculó a la Inquisición con el objeto de evitar ciertos procesos judiciales de la administración civil, pues con la pertenencia a dicha institución quedaban fuera de la jurisdicción de los virreyes. Por tanto, se produjo una limitación del poder virreinal en el aspecto jurídico, ya que una importante parte de la población, los familiares de la Inquisición, permanecieron fuera de su control ${ }^{55}$.

No obstante, el virrey contó con el apoyo de una serie de oficiales entre los que destacaron el consultor, el conservador del Real Patrimonio y el juez de la Monarquía. Los elegidos para estos tres cargos debían ser españoles.

El consultor tenía como función el asesoramiento del virrey en materia jurídica, estando presente en todos los consejos en los que estuviese el virrey. Además podía asistir a las reuniones de los tribunales del reino aunque sólo con voz.

El conservador del Patrimonio, como veremos más adelante, se encargaba de la supervisión de los asuntos económicos del reino y de la actuación del Tribunal del Real Patrimonio. 209.

${ }^{54}$ M. RIVERo Rodríguez (1989). «Doctrina y práctica política en la monarquía hispana...», p.

${ }^{55}$ H. G. KoENIGSBERGER (1989). La práctica ..., pp. 184-186. 
El juez de la Monarquía presidía el Tribunal de la Regia Monarquía encargado de los asuntos religiosos del rey español en su función de legado papal en Sicilia. ${ }^{56}$

Pero la Regencia no sólo contó con la figura del virrey para ejercer su autoridad en la isla frente a las instituciones regnícolas. También disfrutó, como en los reinados anteriores, de una serie de instituciones en las que podía influir como eran la Inquisición, la Monarchia Sicula y el Sindacato.

Con respecto a la Monarchia Sicula debemos remontarnos al siglo XVI y encontrar su explicación en las luchas por el poder entre la Corona y la Iglesia en la isla de Sicilia. En 1513 se produjo el hallazgo de una copia de un documento por el que el papa Urbano II concedía, en 1098, al conde Roger de Sicilia y a sus herederos los derechos y privilegios de legado apostólico en reconocimiento a los servicios prestados a la Iglesia en su lucha contra los sarracenos. Este documento fue utilizado por los soberanos españoles para justificar su suprema autoridad judicial o Monarchia sobre la Iglesia siciliana, lo que generó continuas disputas con el Papado, pues los papas no podían admitir que un laico tuviera mayores poderes eclesiásticos que el pontífice ${ }^{57}$.

Para los sicilianos la Monarchia significaba tener la máxima autoridad eclesiástica pues las funciones judiciales eran ejercidas por jueces eclesiásticos nombrados por el virrey y asistidos por los jueces de la Gran Corte o del Tribunal de la Sacra Conciencia ${ }^{58}$. La Monarchia se convirtió, también, en un aliado más del poder real al permitir al monarca actuar como vice-Papa del reino y del Tribunal de la Regia Monarquía con competencia en la justicia eclesiástica, supervisando a los obispos, sacerdotes y religiosos repartidos por el virreinato ${ }^{59}$. De esta manera, los

${ }^{56}$ Cfr. L. A. Ribot García (1982). La Revuelta antiespañola de Mesina ..., p. 39.

${ }^{57}$ Cit. H. G. Koenigsberger (1989). La práctica..., pp. 166-168. Véase también en L. ScAlisi (2004). Il controllo del sacro. Poteri e istituzioni concorrenti nella Palermo del Cinque e Seicento. Roma: Viella, p. 17.

${ }^{58}$ Véase en H. G. Koenigsberger (1989). La práctica..., p. 166 y ss. Estos jueces, según el autor, oían las apelaciones de los tribunales metropolitanos a la vez que juzgaban en primera y segunda instancia los casos de apelación de desagravio por una de las partes. No existían unas reglas oficiales para el procedimiento y la influencia de los jueces laicos en esta institución provocó que el derecho canónico cediese en más de una ocasión ante el derecho secular siciliano.

59 Cfr. L. A. Ribot García (1982). La Revuelta antiespañola de Mesina ..., p. 39. Según L. Scalisi, para legitimar el poder del Rey en la isla, el virrey Juan de Vega promovió la elaboración del Liber Regia Monarchiae. En él se establecía que los derechos del monarca en la isla eran: «conoscere in primo grado le cause degli esenti e di coloro che si appellavano alla Santa Sede; di conoscere in secondo grado gli appelli ai giudizi dei vescovi e degli arcivescovi (cause civili, criminali, matrimoniali, diritti di asilo, reati di usura, lenocinio e simonía); di conoscere gli appelli alle sentenze 
jueces permanentes tenían que jurar conservar sus derechos, mientras se impedía al clero sus apelaciones a Roma y quedaba en manos del virrey el control de las interferencias no solicitadas de la Curia, suspendiendo el exequatur a los breves papales ${ }^{60}$. Todo ello conllevó las constantes protestas papales que se sucedieron hasta que en 1867 el papa Pío IX abolió definitivamente la Monarchia ${ }^{61}$.

La Inquisición fue introducida en Sicilia por los Reyes Católicos y, como en el caso español, representaba la soberanía espiritual del Papa y la soberanía temporal del rey pese a que sus dos inquisidores sólo estaban subordinados al Consejo Supremo de la Inquisición de Madrid. Dicha institución tenía como función la preservación de las creencias religiosas del pueblo, logrando con ello la fidelidad del pueblo siciliano a la Monarquía Católica ${ }^{62}$. Se pretendía con ello obtener un instrumento con el que mantener por parte de la Monarquía un fuerte control real sobre la isla ${ }^{63}$.

Estaba integrada, además de los dos inquisidores nombrados por la Suprema, por una serie de consejeros, el personal teológico, legal y financiero, así como una potente red de familiares. La Inquisición de Sicilia contó con numerosos familiares debido a que en 1549 un decreto real situó a esta institución fuera de la jurisdicción del gobierno civil, con lo que sus miembros mantuvieron el privilegio de ser juzgados por los tribunales de la Inquisición en causas civiles y criminales. Este hecho dio lugar a un notable incremento en el número de personas de todos los estamentos sociales que intentaron convertirse en familiares del Santo Oficio, eludiendo sus responsabilidades en determinados actos delictivos y, por tanto, de

pronunciate dai delegati apostolici per le cause civili dei regolari; di conoscere in secondo grado le cause civili e criminali degli ordini militari con privilegio di foro; di annullare le sacre vestizioni; di reclamare tutte le cause ecclesiastiche per viam saltus: di annullare, su istanza delle parti, le disposizioni delle autorità ecclesiastiche avocando la trasmissione degli atti originari qualora si supponessero delle irregolarità nella procedura giudiziaria», Cit. L. SCALISI (2004). Il controllo del sacro..., pp. 17-18.

${ }^{60}$ Ibidem., pp. 168-169.

${ }^{61}$ Ibidem., p. 170.

62 Véase H. G. Koenigsberger (1989). La práctica..., pp. 183-185; M. Rivero RodríGueZ (2000). «La Inquisición española en Sicilia (siglos XVI al XVIII)». En B. EsCANDELL BoneT y J. Pérez Villanueva (dirs.). Historia de la Inquisición en España y América. Madrid: Biblioteca de Autores Cristianos, vol. III, p. 1.035.

${ }^{63}$ V. SCIUTI RUSSI (1983). Astrea in Sicilia. Il ministerio togato nella società siciliana dei secoli XVI e XVII. Napoli: Casa Editrice Jovene, p. 139; M. RIVERo RODRÍGUEZ (2000). «La Inquisición española en Sicilia...», p. 1048. 
ciertas prácticas judiciales como el empleo de la tortura ${ }^{64}$. En este sentido, la propia institución invitó a los miembros de la nobleza a unirse a ella, con lo que aumentó su autonomía frente al poder de los virreyes, pues en determinados incidentes surgieron dos grupos, aquel formado por los nobles que se oponían a los virreyes y se unieron a la Inquisición y otro compuesto por quienes apoyaron a los virreyes frente a los inquisidores ${ }^{65}$. Así, el poder adquirido por este organismo le permitió en el siglo XVII mantener a un gran número de sus inquisidores en puestos de la administración española como jueces de la Monarchia, consultores del virrey, visitadores de los dominios de la Corona, etc. ${ }^{66}$. Con todo, el Santo Oficio de Sicilia experimentó un proceso paulatino de decadencia a partir de la segunda mitad de dicho siglo, disminuyendo su papel político y su influencia sobre la sociedad siciliana ${ }^{67}$.

Finalmente, en el Sindacato, institución de corte administrativo, estaban integrados los sindacadores, es decir, veinticuatro letrados encargados de efectuar la residencia a los oficiales que habían ejercido su cargo durante el año anterior. Los sindacadores eran elegidos anualmente por el virrey entre los jueces de los otros tribunales ${ }^{68}$.

\section{LAS INSTITUCIONES DEL REINO EN SICILIA}

En la administración territorial de Sicilia destacaron toda una serie de instituciones que sirvieron de complemento al gobierno del virrey: el Sacro Regio

${ }^{64}$ Ibidem., p. 144; H. C. LEA (1908). The Inquisition in the Spanish Dependencies: Sicily, Naples, Sardinia, Milan, The Canaries, Mexico, Peru, New Granada. London: Macmillan, pp. 27-28.

${ }^{65}$ H. G. Koenigsberger (1989). La práctica ..., pp. 186-187.

${ }^{66}$ V. SCIUTI RUSSI (1983). Astrea in Sicilia. Il ministerio togato..., p. 139.

67 V. SCIUTI RUSSI (2004). «La Inquisición española en Sicilia». Studia histórica. Historia moderna, 26, p. 77. De hecho, durante el siglo XVII descendieron los procesos celebrados por la Inquisición de Sicilia, aunque la institución continuó manteniendo su función de control social, destinando sus esfuerzos a vigilar la lealtad de las personas nombradas para ejercer cargos de gobierno, justicia o administración. Esta labor se incrementó desde la revuelta de 1647, convirtiéndola en un instrumento esencial para asegurar la conservación del reino de Sicilia en manos de la Monarquía Hispánica. Véase en M. RIVERo RodRíGUEZ (2000). «La Inquisición española en Sicilia...», pp. 1196-1203.

68 J. M. DE Bernardo Ares (1995). «La Hacienda del Reino de Sicilia y las necesidades de la Monarquía Hispánica en la segunda mitad del siglo XVII». En Seminario de Humanidades Agustín Millares Carlo, Homenaje a Antonio de Béthencourt Massieu. Las Palmas de Gran Canaria: Cabildo Insular de Las Palmas de Gran Canaria, p. 251; J. M. GARCíA MARTín (1992). Monarquía Católica en Italia. Burocracia imperial y privilegios constitucionales. Madrid: Centro de Estudios Constitucionales, pp. 188-189. 
Consiglio, la Gran Corte, el Tribunal del Consistorio, el Tribunal del Real Patrimonio, el Parlamento General y la Diputación del Reino.

El Sacro Regio Consiglio era una asamblea extraordinaria formada por un número variable (entre 27 y 29) de los miembros más importantes de los tres tribunales supremos (Gran Corte, Real Patrimonio y Consistorio) junto con el tesorero general, el maestro secreto, el consultor del virrey y los oficiales militares que fuesen necesarios ${ }^{69}$. Su cometido era el de la publicación de nuevas leyes y órdenes, así como la toma de decisiones políticas importantes. Desde el siglo XVI comenzó a ser sustituido por una Junta de los presidentes de los tres tribunales más importantes de la administración y de gobierno y el consultor, que actuaba como último tribunal de apelación de los tribunales sicilianos. Paulatinamente fue adquiriendo mayor poder en los asuntos importantes de gobierno y una vez tomada una decisión, ésta era comunicada por los presidentes a sus respectivos tribunales y posteriormente aceptada, mermando así las funciones del Consejo, que se mantuvo para registrar las aprobaciones de las decisiones tomadas por el virrey y la junta ${ }^{70}$.

El reino de Sicilia contaba con tres tribunales supremos y autóctonos. Estaban controlados por el virrey lo que no les impidió conservar ciertas atribuciones de gobierno. Estos eran la Gran Corte, el Tribunal del Real Patrimonio y el Tribunal del Consistorio o de la Sacra Conciencia ${ }^{71}$.

La Gran Corte era el tribunal de la justicia civil y criminal. Actuaba sobre los sicilianos no adscritos a fueros particulares y estaba compuesto por un presidente, seis jueces que ejercían su cargo durante dos años, tres para causas civiles y otros tres para las causas criminales; un abogado fiscal, tres procuradores fiscales, un solicitador y un maestre notario ${ }^{72}$. En la Gran Corte Criminal se trataban las causas criminales, las causas en primera instancia y otras por vía de recurso. Por su parte, la Gran Corte Civil procedía en las causas civiles entre partes y en primera

69 A principios del siglo XVII los miembros eran los tres presidentes de la Gran Corte, Patrimonio, el consultor del virrey, seis jueces de la Gran Corte, seis miembros racionales, el tesorero general, el conservador, dos abogados fiscales que son los de la Gran Corte y Patrimonio, tres jueces del Consistorio, el protonotario, el maestre portulano y el maestre secreto. Véase en P. CELESTRE (1984). «Idea del govierno del reyno de Sicilia», V. ScIUTI RuSSI. Il Governo della Sicilia in due Relazioni del Primo Seicento. Napoli: Jovene Editore, p. 18.

${ }^{70}$ Cit. H. G. Koenigsberger (1989). La práctica ..., pp. 116-117. Véase también L. A. Ribot GARCíA (1982). La Revuelta antiespañola de Mesina ..., p. 38; A. BAVIERA AlbANeSE (1981). Diritto pubblico e istituzioni amministrative in Sicilia: Le fonti. Roma: Il Centro di Ricerca, p. 100.

${ }^{71}$ Cfr. L. A. Ribot García (1982). La Revuelta antiespañola de Mesina ..., p. 39.

${ }^{72}$ Ibidem., p. 39. 
instancia, o en segunda instancia por vía de apelación, revisión o gravamen del reino ${ }^{73}$.

El Tribunal del Real Patrimonio o Regia Camera tuvo como función principal la supervisión de la política interior del reino, la economía y las finanzas. Entre sus atribuciones ejercía también de tribunal en las causas de patrimonio real y de los bienes de la colectividad del reino. Sin embargo, no podía tratar los asuntos religiosos y la justicia civil y criminal. Estaba compuesto por un presidente y seis maestres racionales, tres llamados de toga o cappa longa, que eran juristas, y otros tres de capa y espada o cappa corta, que eran nobles. A ellos se unían toda una serie de maestres racionales con distintas competencias, un abogado fiscal, un procurador, un solicitador y un maestre notario ${ }^{74}$. Por cada uno de los tres valles de la isla se asignaba un maestre racional de cada tipo, siendo los juristas los encargados de las cuestiones relacionadas con la justicia, mientras los legos acudían a los asuntos que no estaban vinculados directamente con la justicia ${ }^{75}$. Como dependientes de este tribunal había toda una serie de cargos con distintas capacidades, entre los que destacaron ${ }^{76}$ :

1. El gobierno frumentario se encargaba de la recepción de un tipo de información que se debía enviar todos los años al Tribunal del Real Patrimonio. En él se tenía en cuenta el trigo, la cebada y las legumbres que se sembraban y recogían en Sicilia. Con dicho recuento y con las noticias que llegaban a manos del presidente y de los maestres racionales, se podía obtener la información suficiente para considerar la cosecha de un año estéril, abundante o mediocre y actuar en consecuencia, según el resultado.

\footnotetext{
${ }^{73}$ Para una descripción detallada de las funciones y procedimientos de la Gran Corte Criminal y de la Gran Corte Civil, véase en P. Celestre (1984). «Idea del govierno del reyno de Sicilia...», pp. 19-24.

${ }^{74}$ L. A. Ribot García (1982). La Revuelta antiespañola de Mesina ..., pp. 39-40.

${ }^{75}$ Los maestres racionales de capa y espada tenían también entre sus funciones: «los negocios y superintendencias de la milicia del Reyno, alojamientos, embarcaciones, pagamentos de soldados, provisiones de castillos, presidios, fiscalias, fábricas de quarteles para alojamientos de soldados, adereços de artillería, armas, pólvora, balas, cuerda, salnitres, instrumentos de guerra, Cruzada, seccas, herrerías, vizcochos, venta de officios, fábricas, armamentos, y provisiones de galeras, arrendamientos de la Corte, de iglesias vacantes del real patronazgo, espolios de prelados difuntos, compras, ventas, cambios, fletes y seguridades, demás de las superintendencias del maestre portulano, maestre secreto, secretos de Palermo, Messina, Catania, Çaragoça y Termines, perceptores y racionales...». Véase en P. Celestre (1984). «Idea del govierno del reyno de Sicilia...», pp. 24-25.

${ }^{76}$ Ibidem., pp. 28-36.
} 
2. El Abogado fiscal del Patrimonio, quien tuvo como objetivo el pedir y defender las causas y pleitos del fisco. Asimismo, intervenía en las conferencias y consejos patrimoniales para proponer el interés del Rey en relación a los negocios tratados en ellos.

3. Los siete racionales, ayudados por ocho coadjutores, que tenían por función la evaluación de las cuentas de los ministros encargados del dinero y de la hacienda del Rey.

4. El cargo de conservador que solía recaer en un caballero de capa y espada de origen extranjero, cuya función era la de supervisar toda entrada y salida de dinero de las arcas de la Corona. Pagos como el de la infantería, caballería, galeras, castillos y gente de guerra, dependían de su intervención.

5. El tesorero general era el ministro pecuniario de mayor consideración y estaba obligado a comunicar semanalmente al virrey los ingresos y gastos producidos en la hacienda. Además, mensualmente debía referir al virrey las deudas que estaban en proceso de cobro y las medidas aplicadas al efecto. A su vez, dichas medidas tenía que comunicarlas por escrito cada cuatro meses al racional encargado de revisar las cuentas.

6. El maestro portulano era el responsable de todo lo relacionado con el trigo. Actuaba como superior de los cargadores del reino ${ }^{77}$ recibiendo todas las órdenes del virrey relacionadas con el aprovisionamiento y la comercialización de dicho cereal.

La importancia de este tribunal por el carácter económico de sus funciones generó, en algunas ocasiones, disputas entre los miembros de éste y la figura del virrey a la hora de tomar ciertas decisiones.

Entre los problemas surgidos entre ambas instituciones estuvo el de la dilación con la que en algunos casos el Tribunal del Real Patrimonio tomaba las decisiones y órdenes dadas por el virrey de Sicilia. Fue este el caso de la petición por parte del duque de Alburquerque al tribunal de una relación de las necesidades defensivas más urgentes del virreinato y de los recursos con los que se podía hacer frente a tales exigencias. Dicha solicitud la había realizado el virrey el 8 de mayo de 1667 pese a lo que tuvo que esperar hasta principios de agosto para recibir una contestación por parte del tribunal. De ahí que, en carta del 24 de agosto, el duque

\footnotetext{
${ }^{77}$ Los cargadores eran en Sicilia los lugares donde se depositaba el trigo bajo fe pública hasta su traslado a otros lugares de dentro o fuera del reino. Véase en P. CELESTRE (1984). «Idea del govierno del reyno de Sicilia...», p. 39.
} 
mostrase su disconformidad ante el trabajo del tribunal, especialmente por la dilación en la toma de decisiones, y por los defectos de forma de la relación remitida al incluir recursos de los que el virrey no podía valerse para mejorar la defensa de la isla ${ }^{78}$.

Otros inconvenientes fueron los que aparecieron cada vez que un virrey pedía recursos al tribunal con el fin de socorrer a otros territorios de la Monarquía. En estas circunstancias el tribunal se mostraba contrario a la aprobación de las ayudas alegando que debían darse prioridad a las necesidades del reino antes de plantearse el apoyo de otras urgencias exteriores. Es el caso de la petición realizada por el duque de Alburquerque con el objetivo de suministrar el grano necesario para el abastecimiento de las tropas que debían pasar desde el frente portugués al catalán en 1668. Una petición ante la cual el tribunal se opuso alegando la falta de grano para el reino y la propia necesidad de la isla que había tenido que recurrir al grano de Nápoles ${ }^{79}$. Estas dificultades ya habían surgido con la petición de un cargamento de pólvora que había efectuado la Corona en 1667 para remitirlo a España. En un principio, el tribunal se había opuesto al envío y sólo por la mediación de Luis del Hoyo, conservador del Real Patrimonio, se obtuvo la aprobación por parte del tribunal de remitir mil cántaros de este producto ${ }^{80}$.

Por último, el Tribunal de la Sacra Conciencia o Consistorio, creado por Felipe II como tribunal de apelación y revisión de las causas ya vistas en la Gran Corte Civil y en el Tribunal del Real Patrimonio, venía a personificar la conciencia del príncipe. El tribunal, cuyas sentencias eran inapelables, estaba compuesto por un presidente, tres jueces bienales y un maestre notario perpetuo ${ }^{81}$.

El Parlamento de Sicilia era una asamblea de origen medieval que en la época de los normandos y suevos había tenido entre sus funciones la aprobación de los impuestos y la resolución de los asuntos políticos y legislativos más importantes. Con el rey aragonés Federico II se estableció la obligatoriedad de que las imposiciones tributarias y las declaraciones de guerra o los tratados de paz contaran con el consentimiento de los representantes de las ciudades. Durante los siglos XIV y XV la influencia aragonesa se hizo presente en la evolución de esta institución

${ }^{78}$ A.G.S., Secretarías Provinciales, leg. 1.184., doc. Palermo, 24 de agosto de 1667.

79 A.G.S., Estado, leg. 3.491, doc. 64.

${ }^{80}$ A.G.S., Estado, leg. 3.490, doc. 73.

${ }^{81}$ L. A. Ribot García (1982). La Revuelta antiespañola de Mesina ..., p. 40. Véase también H. G. Koenigsberger (1989). La práctica ..., p. 98. Para su funcionamiento interno, véase P. Celestre (1984). «Idea del govierno del reyno de Sicilia...», p. 43. 
estableciéndose una asamblea de tres cámaras conocidas como bracci, a semejanza de los brazos aragoneses ${ }^{82}$.

En el siglo XVI evolucionó hacia su forma definitiva caracterizándose por ser una institución convocada por el rey o en su ausencia por el virrey, con el objeto de aprobar la concesión de los donativos, pues sus funciones en política exterior pasaron a depender de la Monarquía Hispánica. No obstante, el Parlamento era informado de las decisiones aprobadas en materia de política exterior y de la lucha contra los otomanos ${ }^{83}$.

Esta institución, cuyo fin principal era la defensa de los capítulos y privilegios del reino, contaba con: el braccio ecclesiastico, compuesto por el alto clero del reino siciliano; el braccio militare, formado por los barones y feudatarios; y el braccio demaniale, integrado por los representantes de las ciudades y distritos de dominio real ${ }^{84}$. De estos tres, los más problemáticos eran el eclesiástico y demanial pues a diferencia de los barones, les afectaba el pago de los impuestos aprobados lo que generó disputas con los virreyes. Estos últimos procuraban obtener una mayoría que apoyase sus exigencias pues de lo contrario el fracaso podía conllevarles su destitución ${ }^{85}$.

La Diputación del Reino de Sicilia estaba integrada por una comisión permanente de doce miembros del Parlamento, cuatro por cada brazo, con la obligación de reunirse semanalmente y ocuparse de la vigilancia de los capítulos y privilegios del reino, así como del reparto de los donativos aprobados en el Parlamento en los periodos de tiempo intermedios entre la convocatoria trianual del Parlamento. Además, tenía asignadas otras funciones como los transportes, las fortificaciones costeras, la recaudación de impuestos, la supervisión del trabajo de los tres perceptores y el nombramiento de los encargados de las torres de costa, caminos y puentes ${ }^{86}$.

${ }^{82}$ Cit. H. G. Koenigsberger (1989). La práctica ..., p. 171; C. Giardina (1931). «L’istituto vicerè...», p. 287.

${ }^{83}$ Ibidem., pp. 171-172. Para profundizar en el poder del Parlamento siciliano durante el gobierno de la dinastía de los Habsburgo, que habría sido menor a la de épocas anteriores, véase en $\mathrm{H}$. G. Koenigsberger (1967). «The Parliament of Sicily and the Spanish Empire». En Mélanges Antonio Marongiu. Palermo: Università di Palermo, Istituto di Storia Medievale, pp. 81-96.

${ }^{84}$ L. A. Ribot GARCía (1982). La Revuelta antiespañola de Mesina ..., p. 41.

${ }^{85}$ H. G. KoenigsBerger (1989). La práctica ..., pp. 175-180.

${ }^{86}$ Ibidem., pp. 181-182. Véase también P. Celestre (1984). «Idea del govierno del reyno de Sicilia...», p. 49; A. BAVIERA Albanese (1981). Diritto pubblico..., p. 103. 
Al margen de estas instituciones y a un nivel institucional inferior existían en el reino una serie de oficiales encargados de la administración y gobierno de Sicilia, tanto en el ámbito de la justicia como en el de la Hacienda. Entre los oficiales de justicia estaban los capitanes de justicia encargados de las causas sencillas y de remitir a la Gran Corte las que superaban sus competencias, así como los capitanes de armas y los capitanes de campaña destinados a la persecución de ladrones y delincuentes. Por su parte, entre los oficiales de finanzas estaban: el maestre portulano, que contaba con una serie de portulanos para la administración de los cargadores del reino; el maestre secreto, junto con una serie de secretos repartidos por las principales ciudades demaniales para la recaudación de la secrecías y aduanas del reino; el tesorero general del reino, encargado entre otras funciones de la administración de los ingresos y rentas reales; y los tres perceptores ocupados en la recaudación de los donativos ${ }^{87}$.

Para terminar este apartado sobre las instituciones del reino de Sicilia cabe mencionar la administración local de las ciudades, villas y lugares del reino en donde se hallaban los jurados, elegidos por los señores en las ciudades o lugares de jurisdicción baronal, nombrados por el virrey en las ciudades «demaniales» o de jurisdicción real, o elegidos a través del sistema de insaculación, de tradición aragonesa, en casos como el de Messina, Catania o Siracusa. Los jurados eran supervisados por el poder central a través de los maestres jurados que revisaban las finanzas de los gobiernos locales y dirigían las actuaciones de sus oficiales ${ }^{88}$.

\section{CONCLUSIONES}

Durante la regencia de Mariana de Austria el Mediterráneo continuó siendo uno de los ámbitos clave para la política exterior de la Monarquía Hispánica. En esta época, el Mediterráneo, fue centro de atención de los intereses de potencias como Francia, el Imperio Otomano, Inglaterra, Holanda y España. De hecho, uno de los temores de la Corona española fue la expansión en dicho mar de sus dos grandes enemigos: Francia y el Imperio Otomano.

La Monarquía española contaba con una serie de dominios en esta zona que podían verse afectados por estas dos potencias. Uno de ellos era la isla de Sicilia, fundamental para la estrategia defensiva de la monarquía, ya que constituía un antemural de la Cristiandad frente al Otomano, a la vez que servía junto a las otras posesiones mediterráneas para potenciar la posición española en Centroeuropa y el Mar del Norte.

${ }^{87}$ Cfr. L. A. RiBot GARCía (1982). La Revuelta antiespañola de Mesina ..., pp. 41-42.

${ }^{88}$ Ibidem., p. 43. 
No obstante, para mantener esta isla dentro de la estrategia española, se hizo necesaria la existencia de una serie de instituciones dependientes del rey o del reino. En este sentido, la Corona contó para su gobierno con organismos como el Consejo de Italia, el Consejo de Estado, la Inquisición, la Monarchia Sicula, el Sindacato y la figura del Virrey. Por su parte, el reino mantuvo otra serie de instituciones propias que contribuyeron a este mismo fin, como son los casos del Sacro Regio Consiglio, la Gran Corte, el Tribunal del Real Patrimonio, el Tribunal de la Sacra Conciencia, el Parlamento, la Diputación, los oficiales de justicia y hacienda, así como la administración local de las ciudades, villas y lugares del virreinato.

\section{BIBLIOGRAFÍA}

AlCALÁ-ZAmora Y QUeIPo DE Llano, J. (1976). «Razón de Estado y geoestrategia en la política italiana de Carlos II: Florencia y los Presidios (1677-1681)». Boletín de la Real Academia de la Historia, 173, pp. 297-358.

Alonso ACERo, B. (2000). Orán-Mazalquivir, 1589-1639: una sociedad española en la frontera de Berbería. Madrid: Consejo Superior de Investigaciones Científicas.

Álvarez-Ossorio Alvariño, A. (2001). «Neoforalismo y Nueva Planta: el gobierno provincial de la monarquía de Carlos II en Europa». En AlCALÁ-ZAMORA Y QUEIPO DE Llano, J. y Belenguer, E. (coords.). Calderón de la Barca y la España del Barroco. Madrid: Centro de Estudios Políticos y Constitucionales, vol. I, pp. 1.061-1.089.

AURIA, V. (1697). Historia cronologica delli signore vicere di Sicilia: dal tempo che mancò la personale assistenza de'Serenissimi Rè di quella: cioe dall anno 1409 sino al 1697 presente. Palermo: Pietro Coppola.

AYMARD, M. (1972). «Bilancio d'una lunga crisi finanziaria». Rivista Storica Italiana, LXXXIV, IV, pp. 988-1.021.

BARrios, F. (1984). El Consejo de Estado de la Monarquía Española (1521-1812). Madrid: Consejo de Estado.

Baviera Albanese, A. (1981). Diritto pubblico e istituzioni amministrative in Sicilia: Le fonti. Roma: Il Centro di Ricerca.

BAVIERA AlBANESE, A. (1998). «I ventisette giorni di 'governo' nel regno di Sicilia di Eleonora de Moura y Moncada, marchesa di Castel Rodrigo (16 aprile-13 maggio 1677)». Archivio Storico Siciliano, IV Serie, XXIX, fasc. 1, pp. 267-303.

Bernardo Ares, J. M. de. (1995). «La Hacienda del Reino de Sicilia y las necesidades de la Monarquía Hispánica en la segunda mitad del siglo XVII». En Seminario de Humanidades Agustín Millares Carlo, Homenaje a Antonio de Béthencourt Massieu. Las Palmas de Gran Canaria: Cabildo Insular de Las Palmas de Gran Canaria, pp. 241261.

Blasi Gambacorta, G. E. di (1790). Storia Cronologica dei vicerè, luogotenenti, e presidenti del Regno di Sicilia. Palermo: Dalle Stampe di Solli.

Braudel, F. (2005). El Mediterráneo y el mundo mediterráneo en la época de Felipe II. $2^{\mathrm{a}}$ ed. $6^{\mathrm{a}}$ reimp. México: Fondo de Cultura Económica. 
Brogini, A. (2006). Malta, frontière de Chrétienté (1530-1670). Rome: École Française de Rome.

BunEs IBARRA, M. A. de. (2010). «El control de la información del Mediterráneo desde Nápoles y Sicilia en la época de Felipe III». En J. MARTínez Millán y M. RIVERO RODRÍGuEz (coords.), Centros de Poder Italianos en la Monarquía Hispánica (siglos $X V$-XVIII). Madrid: Polifemo.

CAlabria, A. (2002). The cost of empire. The finances of the Kingdom of Naples in the Time of Spanish Rule. Cambridge: University Press.

CORTÉs CORTÉS, F. (1996). Alojamientos de soldados en la Extremadura del siglo XVII. Mérida: Editora Regional de Extremadura.

DAy, J., ANATRA, B. y SCARAFFIA, L. (1984). La Sardegna mediovale e moderna. Torino: UTET.

Elliott, J. H. (2005). La España Imperial, 1469-1716. Barcelona: Vicens Vives.

FAVArò, V. (2004). «La Sicilia Fortezza del Mediterraneo». Mediterranea. Ricerche storiche, 1, pp. 31-48.

FERnÁNDEZ NADAL, C. M. (2009). La política exterior de la monarquía de Carlos II. El Consejo de Estado y la embajada de Londres (1665-1700). Gijón: Ateneo Jovellanos.

Galasso, G. (2000). En la periferia del Imperio. La Monarquía Hispánica y el Reino de Nápoles. Barcelona: Península.

GARCía MARtín, J. M. (1992). Monarquía Católica en Italia. Burocracia imperial y privilegios constitucionales. Madrid: Centro de Estudios Constitucionales.

GiardinA, C. (1931). «L'istituto vicerè di Sicilia (1415-1798)». Archivio Storico Siciliano, vol. LI, pp. 189-294.

GIUFFrIDA, R. (1976). «La politica finanziaria spagnola in Sicilia da Filippo II a Filippo IV (1556-1665)». Rivista Storica Italiana, LXXXVIII, II, pp. 310-341.

GómEZ-CENTURIón JiMÉnEZ, C. (2001). «La sucesión a la monarquía de España y los conflictos internacionales durante la menor edad de Carlos II (1665-1679)». En Alcalá-ZAmora y Queipo de Llano, J. y Belenguer, E. (coords.). Calderón de la Barca y la España del Barroco. Madrid: Centro de Estudios Políticos y Constitucionales, vol. I, pp. 805-835.

HERnANDO SÁNCHEZ, C. (2004). «Los virreyes de la Monarquía Española en Italia. Evolución y práctica de un oficio de gobierno». Studia Historica. Historia Moderna, 26, pp. 43-73.

HeRrero SÁNCHEZ, M. (2000). El acercamiento hispano-neerlandés (1648-1678). Madrid: Consejo Superior de Investigaciones Científicas.

JAČOV, M. (2001). L' Europa tra conquiste ottomane e leghe sante. Città del Vaticano: Biblioteca Apostolica Vaticana.

KAMEN, H. (2000). «España en la Europa de Luis XIV». En MENÉndeZ PIDAL, R. y Jover Zamora, J. M. Historia de España. Madrid: Espasa, vol. XXXVIII, pp. 205-298.

Koenigsberger, H. G (1967). «The Parliament of Sicily and the Spanish Empire». En Mélanges Antonio Marongiu. Palermo: Università di Palermo, Istituto di Storia Medievale, pp. 81-96.

Koenigsberger, H. G (1989). La práctica del Imperio. Madrid: Alianza Editorial. 
LEA, H. C. (1908). The Inquisition in the Spanish Dependencies: Sicily, Naples, Sardinia, Milan, The Canaries, Mexico, Peru, New Granada. London: Macmillan.

LIGRESTI, D. (1997). «I bilanci secenteschi del Regno di Sicilia». Rivista Storica Italiana, CIX, III, pp. 894-937.

Ligresti, D. (2003). «La Sicilia frontiera». En BENignO, F. y Giarrizzo, G. (a cura di). Storia della Sicilia, vol. I. Roma: Editori Laterza, pp. 134-148.

Ligresti, D. (2007). Sicilia aperta (secoli XV-XVII). Mobilità di uomini e idee. Palermo: Associazione non profit «Mediterranea».

MAFFI, D. (2010). La cittadella in armi. Esercito, società e finanza nella Lombardia di Carlo II (1660-1700). Milano: Franco Angeli.

MANTRAN, R. (1989). Histoire de l'Empire Ottoman. Poitiers: Fayard.

Marrone, G. (1976). L'Economia Siciliana e le finanze spagnole nel Seicento. Caltanissetta-Roma: Salvatore Sciascia Editore.

MARTínez Ruíz, E. (2008). Los soldados del Rey. Los ejércitos de la Monarquía Hispánica (1480-1700). Madrid: Actas.

Maura y Gamazo, G. (1942). Vida y reinado de Carlos II. Madrid: Espasa-Calpe.

Mesa Coronado, M. P. (2012). «Sicilia en la estrategia defensiva del Mediterráneo (16651675)». En SAnZ CAMAÑES, Porfirio (ed.). Tiempo de cambios. Guerra, diplomacia y política internacional de la Monarquía Hispánica (1648-1700). Madrid: Actas.

Musi, A. (a cura di) (1994). Nel sistema imperiale l'Italia spagnola. Napoli: Edizioni scientifiche italiane.

Musi, A. (2001). L'Italia dei Vicerè. Integrazione e resistenza nel sistema imperiale spagnolo. Cava de Tirreni: Avagliano Editore.

Pérez Bustamente, R. (2000). El Gobierno del Imperio Español. Los Austrias (15171700). Madrid: Comunidad de Madrid. Consejería de Educación.

Ribot GarcíA, L. A. (1982). La Revuelta antiespañola de Mesina. Causas y antecedentes (1591-1674). Valladolid: Universidad de Valladolid.

Ribot GarcíA, L. A. (1990). «Milán, plaza de Armas de la Monarquía». Investigaciones Históricas, 10, pp. 203-238.

RiBOT GARCíA, L. A. (2002). La Monarquía de España y la guerra de Mesina (1674-1678). Madrid: Actas.

RIVERO RODRÍGUEZ, M. (1989). «Doctrina y práctica política en la monarquía hispana; Las instrucciones dadas a los virreyes y gobernadores de Italia en los siglos XVI y XVII». Investigaciones históricas: época moderna y contemporánea, 9, pp. 197-214.

Rivero Rodríguez, M. (1998). Felipe II y el Gobierno de Italia. Madrid: Sociedad Estatal para la Conmemoración de los Centenarios de Felipe II y Carlos V.

Rivero RodríGueZ, M. (2000). Diplomacia y relaciones exteriores en la Edad Moderna. 1453-1794. Madrid: Alianza Editorial.

RIVERO RODRÍGUEZ, M. (2000). «La Inquisición española en Sicilia (siglos XVI al XVIII)». En B. Escandell Bonet y J. Pérez Villanueva (dirs.). Historia de la Inquisición en España y América. Madrid: Biblioteca de Autores Cristianos, vol. III, p. 1.031-1.222.

RiVERo RodrígUEZ, M. (2004). «Italia en la Monarquía Hispánica (siglos XVI-XVII)». Studia Historica. Historia Moderna, 26, pp. 19-41. 
RiVERo Rodríguez, M. (2008). «Una monarquía de casas reales y cortes virreinales». En J. Martínez Millán y M. A. Visceglia (coords.). La monarquía de Felipe III. Madrid: Mapfre, vol. I, pp. 31-60.

RiVERo RodríGUEZ, M. (2009). «Virtud cristiana de la nobleza de Sicilia: La interrupción de la asistencia de los blancos de Palermo a los ajusticiados (1670-1675)». En M. Rivero Rodríguez (ed.). Nobleza hispana, nobleza cristiana. La Orden de San Juan. Madrid: Polifemo, vol. I, p. 619-673.

Rivero Rodríguez, M. (2011). La edad de oro de los virreyes. El virreinato en la Monarquía Hispánica durante los siglos XVI y XVII. Madrid: Akal.

SAlinAS, D. (1989). La diplomacia española en las relaciones con Holanda durante el reinado de Carlos II (1665-1700). Madrid: Ministerio de Asuntos Exteriores.

SÁNCHEZ BELÉN, J. A. (1999). «Las relaciones internacionales de la monarquía hispánica durante la regencia de doña Mariana de Austria». Studia Historica. Historia Moderna, 20, pp. 137-172.

Sanz Camañes, P. (1997). Política, hacienda y milicia en el Aragón de los últimos Austrías entre 1640 y 1680. Zaragoza: Institución «Fernando el Católico».

SAnZ CAMAÑES, P. (2004). «El peso de la milicia. 'Alojamiento foral' y conflicto de jurisdicciones en la frontera catalano-aragonesa durante la guerra de Cataluña (16401652)». Revista de Historia Moderna, 22, pp. 173-207.

SCALISI, L. (2004). Il controllo del sacro. Poteri e istituzioni concorrenti nella Palermo del Cinque e Seicento. Roma: Viella.

ScIUTI RUSSI, V (1983). Astrea in Sicilia. Il ministerio togato nella società siciliana dei secoli XVI e XVII. Napoli: Casa Editrice Jovene.

ScIUTI RUSSI, V (1984). Il Governo della Sicilia in due Relazioni del Primo Seicento. Napoli: Jovene Editore.

SCIUTI RUSSI, V (2004). «La Inquisición española en Sicilia». Studia histórica. Historia moderna, 26, pp. 75-99.

Setton, K. M. (1991). Venice, Austria, and the Turks in the Seventeenth Century. Philadelphia: The American Philosophical Society.

SHAw, S. J. (1977). History of the Ottoman Empire and Modern Turkey. Cambridge: University Press.

Signorotto, G. (2006). Milán Español. Guerra, instituciones y gobernantes durante el reinado de Felipe IV. Madrid: La Esfera de los Libros.

SolÁ CASTAÑo, E. (2005). Los que van y vienen. Información y fronteras en el Mediterráneo clásico del siglo XVI. Alcalá de Henares: Servicio de Publicaciones. Universidad de Alcalá de Henares.

STORRS, C. (1997), «The Army of Lombardy and the Resilence of Spanish Power in Italy in the Reign of Carlos II (1665-1700). Part I». War in History, 4, pp. 371-397;

STORRS, C. (1998). «The Army of Lombardy and the Resilence of Spanish Power in Italy in the Reign of Carlos II (1665-1700). Part II». War in History, 5, pp. 1-21.

STORRS, C. (2006). The Resilence of the Spanish Monarchy, 1665-1700. New York: Oxford University Press. 
VILLARI, R. (1996). «España, Nápoles y Sicilia. Instrucciones y advertencias a los virreyes». En EnCISO ReCIO, L. M. (coord.). La politica de Felipe II. Dos estudios. Valladolid: Universidad de Valladolid, 1996, pp. 31-52. 